\title{
Predicting Student Engagement in the Online Learning Environment
}

\author{
Abdalganiy Wakjira, Indian Institute of Technology, Guwahati, India \\ Samit Bhattacharya, Indian Institute of Technology, Guwahati, India
}

\begin{abstract}
Students in online learning who have other responsibilities of life such as work and family face attrition. Constructing a model of engagement using the least amount of time is important as it allows us to uncover more subtle patterns. The authors built a student engagement prediction model using nine features that were significant out of 13 features to affect the levels of student engagement. The student engagement prediction model was built using non-linear regression technique from three factors-behavioral, collaboration, and emotional-across a micro-level time scale such as five minutes to identify at-risk students as quickly as possible before they disengage. The accuracy of the model was found to be $83.3 \%$. The results of the study will give teachers the chance to provide early interventions and guidelines for designing online learning activities.
\end{abstract}

\section{KEYWORDS}

Online Engagement, Online Learning, Predicting Engagement, Prediction Model, Student Engagement

\section{INTRODUCTION}

In earlier times, educational opportunities have been limited by the resources within schools. Technology-enabled learning allows learners to access resources anywhere in the world (U.S. Department of Education, 2017). The online learning is sought by those who want to pursue their education while accomplishing the other responsibilities of life such as work and family besides the learning. These students who have burdens of many responsibilities face attrition (Dixson, 2015).

Engagement is defined as "the behavioural intensity and emotional quality of a person's active involvement during a task" (Reeve et al., 2004, p.1). Manwaring et al. (2017) studied engagement at three distinct levels of analysis: the institutional level, the course level, and the activity level. "Activity level engagement has received less attention and research than institutional and course level engagement" (Manwaring et al., 2017, p.2). Student engagement in online learning requires advance study as the online existence of universities has improved. Engagement in the online learning environment never obtained due consideration in the past. (Dixon, 2015).

Moreover, if a student loses interest or is not getting engaged in the e-learning session, the teacher cannot easily monitor as the setting is online learning (Al-Alwani, 2016). And because engagement represents a direct pathway to learning, disengagement (losing interest or not getting engaged) provides barriers to achieving learning outcomes (Hancock and Zubrick, 2015).

Technology-mediated learning provides significant student engagement data which is unavailable in more traditional contexts. Many of the systems used in technology-mediated learning keep records of real-time data about student interactions with the system (Henrie et al., 2015). Husain et al., (2018) applied supervised machine learning algorithms to predict low student engagement from interaction

\section{DOI: 10.4018/IJWLTT.287095}

This article published as an Open Access article distributed under the terms of the Creative Commons Attribution License (http://creativecommons.org/licenses/by/4.0/) which permits unrestricted use, distribution, and production in any medium, provided the author of the original work and original publication source are properly credited. 
in virtual learning environments. Motz et al., (2019) applied logistic regression model through a clustering technique to predict student engagement from interaction in learning management system which is Canvas. Cocea and Weibelzahl (2011) developed a disengagement prediction model on data of an e-learning system called HTML tutor. In these works, the models predicted student engagement from behavioural factors alone. However, engagement needs to be defined as multi factor construct to ensure that the richness of real human experience is understood (Henrie et al., 2015). Sadeque et al., (2015) developed logistic regression model to predict continued participation in an online health forum. However, the features of the discussion forum occurred in health related discussion, not e-learning related. Moreover, the authors discussed that relations between features such as number of replies to someone's post and the time between someone's post and replies he/she got and engagement are unknown. Sharma et al., (2019) also predicted student engagement from emotional factors with facial emotion recognition tools. Moreover, Calvo and D'Mello, (2010) remarked that affect detection systems that integrate data from different factors have been widely advocated but rarely implemented. Kizilcec et al.,(2013) also pointed out that constructing a model of engagement with smallest granule of time has not been implemented widely, but implementing it is important as it allows to uncover more subtle patterns. There are two research questions in this study. These are:

- Can the researchers build student engagement prediction model from three factors: behavioral, collaboration and emotional factors across micro level time scale such as 5 minutes?

- Will collaborative features as a result of interaction in the discussion forum in e-learning environment such as number of replies to someone's post and the time between someone's post and replies he/she got impact the prediction of student engagement levels?

The researchers, therefore aim to build student engagement prediction model using non-linear regression technique from three factors: behavioral, collaboration and emotional factors across micro level time scale such as 5 minutes in an asynchronous online learning environment to identify at risk students as quickly as possible before they disengage (Falkner and Falkner, 2012).

The paper was organized as follows. Literature review was discussed in section 2 . The data collection detail was described in section 3. The analysis of data was presented in section 4. Model building was presented in section 5. Validating the model was described in section 6 . The discussion part was presented in section 7 . Section 8 concludes the paper.

\section{LITERATURE REVIEW}

In literature, the three main factors of engagement constitute behavioural, emotional and cognitive perspective (Redmond et.al., 2018). Within online environments, there are two additional constituencies of engagement: social engagement and collaborative engagement. These five engagement factors are interrelated and interconnected to each other and revealed to be critical for active learner engagement and impact engagement in online learning (Redmond et.al.,2018).

Behavioural engagement is related to the active participation of the learner in academic activities. The learner completes all academic activities, does the work and keeps the rules. Collaborative engagement is the development of different relationships and networks that support learning, including collaboration with peers and instructors. Emotional engagement refers to learner's emotional reaction to learning, his/her feelings or attitudes towards learning.

Social engagement refers to students' social investment in the collegiate experience. It includes participation in academic as well as non-academic activities which occur outside the virtual classroom, such as recreation or social functions, along with discussions of a social nature. Cognitive engagement is the active process of learning. It is related to what students do and think to promote learning (Redmond et.al.,2018). 
Baker and Rossi, (2013) remarked that deciding which factor(s) of engagement to model is a challenge. Not all factors (or aspects of each factor) need to be detected in order to support effective intervention. Specific factors impact learning outcomes and longer-term engagement in different ways, and some are more important to identify and adapt to than others, depending on the learning context.

Accordingly, in our study, we focused on reviewing research papers related to the three factors, namely behavioural, emotional and collaborative factors in technology-mediated learning settings, where engagement can potentially be measured by computer-recorded features such as assignments completed, frequency of postings, responses, and views, time spent creating a post, and time spent online (Henrie et.al., 2015).

\section{Engagement Prediction Models From Behavioral Factors}

Husain et al., (2018) applied supervised machine learning algorithms to predict low student engagement from interaction in virtual learning environment. The features the authors applied include highest education level, final results, score on the assessment and the number of clicks in virtual learning environment (VLE) activities. The machine learning models implemented were Decision Tree, J48, JRIP and gradient boosted algorithm. The output variables were engaged or not engaged. The prediction time the authors applied was weekly, which was very long time scale.

Motz et al. (2019) investigated the relationship between features of student activity derived from $\log$ files of LMS called Canvas and instructors ratings of student engagement. The authors applied logistic regression model through clustering technique to predict student engagement. The authors applied 19 features. Some of these features were time related, number of actions on activities and visits to activities. The prediction time the authors applied is a semester long, which is very long time scale. The output variables in their study were engaged or not engaged.

Cocea and Weibelzahl (2011) developed disengagement prediction model on data of an e-learning systems called HTML tutor. The authors applied 8 data mining methods. These are Bayesian Nets with $\mathrm{K} 2$ algorithm and a maximum of three parent nodes (BN), Logistic regression (LR), Simple logistic classification (SL) that uses the LogitBoost algorithm, Instance based classification with IBk algorithm (IBk), Attribute Selected Classification using J48 classifier, Bagging using REP (reducederror pruning) tree classifier (B), Classification via Regression (CvR) and Decision Trees with J48 classifier. The predicted outputs were engaged, disengaged and neutral variables. They compared three datasets based on number of features. One data set containing 30 features, second data set containing 10 features and the third dataset containing 6 features. The authors applied the dataset containing the three datasets: the one containing 30 features, the one containing 10 features and the one containing the minimum number of features which is dataset containing 6 features. The time scale to predict disengagement is 10 minutes. The engagement levels that may occur at 5 minutes scale could not be predicted by their model.

\section{Engagement Prediction Models From Collaboration Factors}

Sadeque et al., (2015) developed logistic regression model to predict continued participation in an online health forum. The authors applied features such as the number of threads in a post, the number of replies, the number of days from the time of the last post or reply on discussion forum. The authors applied 16 features to predict continued participation. However, the prediction time interval the authors used is 1 month time which is very long time scale compared to prediction time of 5 minutes. Moreover, the features of the discussion forum occurred in health related discussion, not e-learning related. To the best of our knowledge, the effect of these features in the discussion forum in the e-learning environment on the prediction of engagement level has never been studied.

\section{Engagement Prediction Models From Emotional Factors}

Altuwairqi et al. (2018) proposed an affective model that measured student engagement based on their emotions. The authors mapped different emotions to five levels of engagement. These levels 
are strong engagement, high engagement, medium engagement, low engagement and disengagement. The authors used observation of facial expression from recorded videos and self-reporting method to detect the emotions. The authors also applied self-reporting method to detect the level of engagement of participants. The authors analysed 22 emotions in each level of engagement to detect strong emotions. The emotion that was felt by the largest number of participants indicated that the emotion was strongest. That strongest emotion will be mapped to strong engagement level. The time interval used to predict the engagement level was between 7 and 12 minutes, which is not as small time scale as 5 minutes. Sharma et al. (2019) combined information about the movements of the eyes, head, and facial emotions to produce a concentration index with three classes of engagement: "very engaged", "nominally engaged" and "not engaged at all". The model they built recognized a dominant emotion which is an emotion with highest probability score. The concentration index is calculated by multiplying the dominant emotion probability and emotion weight. They developed a model that detected engagement in real time. Sharma et al. (2019) did not consider calculating engagement from different factors other than emotional factor while engagement is a multifaceted construct (D'Mello et al., 2017).

Moreover, providing students with support and guidance as soon as possible to reduce the risk of disengagement is critical (Falkner and Falkner, 2012). Most existing student engagement prediction models, which we reviewed, did not predict student engagement in smaller time scales such as 5 minutes. Table 1 summarizes the student engagement prediction models used with input features and prediction time scales for the three factors namely behavioural, collaboration and emotional.

According to D'Mello et al., (2017), engagement is" a multifactor construct with the fact that the number and nature of the factors are unclear" (p.3). Redmond et al. (2018) on the other hand, found out that within online environments, there are five factors of engagement related to online learning environment: "social engagement, cognitive engagement, behavioural engagement, collaborative engagement, and emotional engagement" (p.7). In our study, we focused on reviewing research papers related to the three factors, namely behavioural, emotional and collaborative factors. Most of the existing works, which we reviewed, did not consider building student engagement prediction models from three factors namely behavioural, collaboration and emotional factors. All the papers above neglected adding the element of collaborative engagement factor while it was explained by Redmond et al., (2018) who assert that individuals' interactions with teachers or other students have been identified as key influencer of engagement. To the best of our knowledge, whether collaborative features during interactions in discussion forum impact the prediction of student engagement levels or not has never been studied as part of multi factor component of student engagement in e-learning environment.

\section{DATA COLLECTION DETAILS}

In this paper, the researchers aim to build student engagement prediction model from three factors: behavioural, collaboration and emotional factors in an asynchronous online learning environment. For achieving the objective, the researchers collected empirical data related to interaction with learning activities in LMS. Further details of data collection are provided in the following subsection.

\section{Experimental Setup}

Two sets of participants were involved for two experiments. One set is for model building experiment and the other is for validating the model experiment. The number of participants for both sets was 12. The type, gender and age of the participants in both sets were different. The participants in the model building experiment were postgraduate students of Indian Institute of Technology Guwahati. Their average age was 33.6, with minimum age of 24 and maximum age of 39 . There were 10 males and 2 females. The participants for validating the model experiment were with minimum age of 23 , and maximum age of 41 and their average age was 31.2. The gender of all was male. Both sets of 
Table 1. Summary of the student engagement prediction models used with input features and prediction time scales for the three factors namely behavioural, collaboration and emotional

\begin{tabular}{|c|c|c|c|c|}
\hline Reference & Factors & Model applied & Input features & $\begin{array}{l}\text { Prediction } \\
\text { time scale }\end{array}$ \\
\hline $\begin{array}{l}\text { Husain } \\
\text { al.(2018) }\end{array}$ & \multirow[t]{3}{*}{$\begin{array}{l}\text { Behavioural } \\
\text { factors }\end{array}$} & $\begin{array}{l}\text { Decision Tree, J48, } \\
\text { JRIP and gradient } \\
\text { boosted algorithm }\end{array}$ & $\begin{array}{l}\text { Highest education level, final results, score on the } \\
\text { assessment and the number of clicks }\end{array}$ & 1 week \\
\hline Motz et al.(2019) & & logistic regression & $\begin{array}{l}\text { Time on asgmt pages (m), Avg time between first } \\
\text { access \& asgmt deadline (h), Avg session duration with } \\
\text { asgmt views (h), Avg page views / session with asgmt } \\
\text { views (c), Visits to 'Files' after an asgmt view (c), } \\
\text { Visits to other 'Assignments' after an asgmt view (c), } \\
\text { Visits to 'Modules' after an asgmt view (c), Visits to } \\
\text { static 'Pages' after an asgmt view (c), Total asgmt } \\
\text { views with no subsequent visit (c), Visits to other } \\
\text { Canvas tools after an asgmt view (c), Number of } \\
\text { asgmt submissions 6am-6pm (c), Number of asgmt } \\
\text { submissions 6pm-midnight (c). Number of asgmt } \\
\text { submissions midnight-6am (c), Total number of } \\
\text { submissions (c), Total visits to asgmt pages before } \\
\text { deadline (c), Total visits to asgmt pages after deadline } \\
\text { (c), Number of unique sessions with site visits (c), } \\
\text { Visits to Canvas's 'Calendar' of assignments (c), } \\
\text { Longest period of inactivity within the site (h) }\end{array}$ & 1 semester \\
\hline $\begin{array}{l}\text { Cocea and } \\
\text { Weibelzahl(2011) }\end{array}$ & & $\begin{array}{l}\text { Bayesian Nets with K2 } \\
\text { algorithm and a } \\
\text { maximum of three } \\
\text { parent nodes (BN), } \\
\text { Logistic regression } \\
\text { (LR), Simple logistic } \\
\text { classification (SL) that } \\
\text { uses the LogitBoost } \\
\text { algorithm, Instance } \\
\text { based classification } \\
\text { with IBk algorithm } \\
\text { (IBk), Attribute } \\
\text { Selected Classification } \\
\text { using J48 classifier, } \\
\text { Bagging using REP } \\
\text { (reduced-error pruning) } \\
\text { tree classifier (B), } \\
\text { Classification via } \\
\text { Regression (CvR) and } \\
\text { Decision Trees with J48 }\end{array}$ & $\begin{array}{l}\text { Number of pages, average time on pages, number of } \\
\text { tests, average time on tests, number of correctly } \\
\text { answered tests, number of incorrectly answered tests }\end{array}$ & 10 minutes \\
\hline $\begin{array}{l}\text { Sadeque et } \\
\text { al.(2015) }\end{array}$ & Collaboration & logistic regression & $\begin{array}{l}\text { PostCount, ReplyCount, SelfReplyCount, } \\
\text { OtherReplyCount, TimeGap1, TimeGap2, AvgDays, } \\
\text { Age, Gender, HasLocation, Haslmage, PosUnigrams, } \\
\text { NegUnigrams, TotalUnigrams, Question, Url }\end{array}$ & 1 month \\
\hline $\begin{array}{l}\text { Altuwairqi et } \\
\text { al.(2018) }\end{array}$ & Emotional & $\begin{array}{l}\text { The emotion that was } \\
\text { felt by the largest } \\
\text { number of participants } \\
\text { indicated that the } \\
\text { emotion was strongest } \\
\text { than others. That } \\
\text { strongest emotion will } \\
\text { be mapped to strong } \\
\text { engagement level. }\end{array}$ & $\begin{array}{l}\text { Surprise, Enthusiastic, Excited, Angry, Ashamed, } \\
\text { Fearful, Nervous, Happy, Content, Delighted, Joyful, } \\
\text { Satisfied, Disgusted, Disappointed, Sad, Bored, } \\
\text { Depressed, Tired, } \\
\text { Sleepy, Relaxed, } \\
\text { Still, Quiet }\end{array}$ & $\begin{array}{l}\text { Between } 7 \text { and } \\
12 \text { minutes }\end{array}$ \\
\hline $\begin{array}{l}\text { Sharma, et } \\
\text { al.(2019) }\end{array}$ & & $\begin{array}{l}\text { The concentration index } \\
\text { is calculated by } \\
\text { multiplying the } \\
\text { dominant emotion } \\
\text { probability and emotion } \\
\text { weight }\end{array}$ & $\begin{array}{l}\text { Emotion shown in the facial expression which can be } \\
\text { one of the seven categories: Angry, Disgust, Fear, } \\
\text { Happy, Sad, Surprise or Neutral }\end{array}$ & Real time \\
\hline
\end{tabular}

participants signed consent forms. Table 2 summarizes the profile of the participants of both the model building experiment and the model validation experiment.

In the study, Moodle was chosen as a learning management system to allow students to interact with learning activities. For every task and participant, the log files of the interaction with the LMS were recorded automatically, at 5 minutes interval. We used version 3.5 on Ubuntu 18.04.

Sample log file of the LMS is shown in Figure 1. 
Table 2. Summary of the profile of participants

\begin{tabular}{|l|l|l|l|l|l|l|l|}
\hline \multicolumn{7}{|l|}{ Model building experiment } & \multicolumn{2}{l|}{} \\
\hline & Gender & Age & LMS experience \\
\hline & Male & Female & Min & Max & Average & Yes, I have & No, I don't have \\
\hline Quantity & 10 & 2 & 24 & 39 & 33.6 & 3 & 9 \\
\hline & Model validation experiment & & \\
\hline & Gender & Age & LMS experience \\
\hline & Male & Female & Min & Max & Average & Yes, I have & No, I don't have \\
\hline & 0 & 23 & 41 & 31.2 & 4 & 8 \\
\hline
\end{tabular}

In our study, we used a facial emotion recognition tool called clmtrackr to capture the facial emotion automatically (Khazan, 2014; Robal et al, 2018). We accessed the source code from web URL: https://github.com/auduno/clmtrackr. We installed version v1.1.2. The tool calculates the recognition rate of six basic emotions: disgust, angry, fear, sad, happy and surprise by getting the model fitting score of the classified image as an emotion. It produces downloadable log file as comma separated value (csv) at the end of the session and offers dialog box in the browser window. It uses timer of elapsed time. Figure 2 shows implementation of clmtrackr to detect the rate of six basic emotions. Sample log file of the facial emotion recognition tool is shown in Figure 3. Figure 4 shows a student interacting with content while his facial emotion was detected in real time.

Four tasks were designed and implemented, which were content viewing, quiz, assignment and discussion forum as online tasks. Content viewing, quiz, and assignment were designed to detect behavioural engagement as explained by Wang and Degol (2014) that engagement can take the form of observable behaviour (e.g., participation in the learning activity, on-task behaviour). According to Husain et al. (2018), content viewing, discussion forum and quiz are significantly correlated with engagement. Assignment is the most used indicator of engagement according to Motz et al. (2019). We have also applied discussion forum to be used as one of the tasks to detect collaborative engagement. According to Redmond et al. (2018) individual interaction of learners with each other has been main influencer of engagement. Moreover, educational technologies such as discussion boards could enhance the learning experience because discussions are captured and can be reviewed later by students and instructors (Salazar, 2010). Table 3 shows summary of tasks performed. There were three factors with a total of 13 features as shown in Table 4.

The participants took part in two experiments, one for model building and the other for validating the model. The participants interacted with four learning activities mentioned in Table 3 while their

Figure 1. Log file saved in the database of Moodle, accessed as MS Excel file and converted into sequence of 5 minutes sample

\begin{tabular}{|c|c|c|c|c|c|c|c|}
\hline 4 & A & B & D & E & F & I & \\
\hline 1 & Timo & Uier full nams & Event content & Component & Event numb & & \\
\hline 47 & $901 / 20,2353$ & Acheniff Acheniff & \multicolumn{2}{|c|}{ Forum: Discussion forum to do the assignment thro Fonum } & Dlscusslon viewed & & \\
\hline 48 & $9 / 01 / 20,23: 52$ & Achenilf Achenilf & Forum: Olscussion forum to do the assignment throf & forven & Course module viewed & & \\
\hline 49 & $9 / 01 / 20,2350$ & Acheniff Achenilf & Course: introduction to Descripthe Stenistics & Spstem & Course vieved & & \\
\hline so & 30/12/19, 09:02 & Achenif Achenif & \multicolumn{2}{|c|}{ Assignment: Assignment to be worked through colli Assignment } & \multicolumn{2}{|c|}{ The status of the submission has been viewed. } & \\
\hline 51 & $30 / 12 / 19.0902$ & Asthenif Asthenif & \multicolumn{2}{|c|}{ Assignmentat Assignment to be worked through colli, Assigrment } & Course madule viewed & & \\
\hline 52 & $30 / 12 / 19,09: 02$ & Achenif Achenif & \multirow{2}{*}{\multicolumn{2}{|c|}{ Assignment: Assignment to be worked through celli Assignment }} & A submission has been subminted. & & \\
\hline 53 & 30/12/19, 09:02 & Achenilf Achenenlf & & & Ceurne acthity completion updered & & \\
\hline s4 & $30 / 12 / 19,09 \cdot 02$ & Achenif Achenilf & \multicolumn{2}{|c|}{ Assignments Assignment to be worked through collt file submissions } & Submission created. & & \\
\hline 55 & 30/12/19,00:02 & Aethenil Aehenit & \multicolumn{2}{|c|}{ Assignment: Assignment to be worked through cellif file submissions } & A fille has beth uplaoded. & & \\
\hline 56 & $30 / 12 / 19,09: 02$ & Achenif Achenif & \multicolumn{2}{|c|}{ Assignmentr Assignmemn to be warked through collt Assignment } & Course moddle vienened & & \\
\hline 57 & $30 / 12 / 19,09: 01$ & Actmenif Achenilf & \multicolumn{2}{|c|}{ Asulgnment: Assignment to be werked throsgh celli, Asrignment } & Shbmission form viewed. & & \\
\hline ss & $30 / 12 / 19,09: 01$ & Achenif Achenilf & \multicolumn{2}{|c|}{ Asignmenti Assignment to be worked through colli, Assignment } & Course nodule viewed & & \\
\hline 59 & $30 / 12 / 19,09: 00$ & Achenit Achenilf & \multicolumn{2}{|c|}{ Assignment: Assignment to be worked through colli, Assignement } & Submission form viewed. & & \\
\hline 60 & 10/12/19, 09:00 & Achenif Achenif & \multirow{2}{*}{\multicolumn{2}{|c|}{ Assignment: Assignment to be worked through colli Assigrment }} & Course module vilened & & \\
\hline 61 & $30 / 12 / 19,09: 00$ & Asthenif Ashenif & & & The stans of the submissier & o verwed. & \\
\hline 62 & $30 / 12 / 19,09.00$ & Achenif Achenif & \multicolumn{2}{|c|}{ Astignmentit Astignment to be worked through colli, Assignment } & Course module viened & & \\
\hline 63 & $30 / 12 / 19,09: 00$ & Achenit Achenif & Course: intreduction to Deserlothe Stentigtics & Syitem & Course vilewed & & \\
\hline 64 & 30/12/19, 08:53 & Achenilf Achenif & \multicolumn{2}{|l|}{ Forvum Oiscusstion forum to do the assignment thro Forom } & Discusiblan vilewed & & \\
\hline 65 & $30 / 12 / 19,08: 52$ & Achenenit Achenenif & \multicolumn{2}{|c|}{ Fervma Descussion forvm to do the assignment thro forum } & Course module virued & & \\
\hline 66 & 30/12/19, 06:52 & Aschenif Aschenif & Course: introduction to Descerlothe Stenisthtss & System & Course vilewad & & \\
\hline 67 & $30 / 12 / 19,0852$ & Acthenil Achenil & Qvin Oule 3 & Quir & Quit attempt revilemed & & \\
\hline 6 & 30/12/19. as:s2 & Acheniff Acheniff & Culi: Oule 3 & Culs & Colit attemgr submitred & & \\
\hline & 30/12/19, 08:52 & Achenit Achenif & Course: Intreduction to Desicrlothe Stuntistics & System & User graded & & \\
\hline & 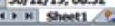 & & & & & & \\
\hline
\end{tabular}


Figure 2. Implementation of cImtrakr to detect the six basic emotions

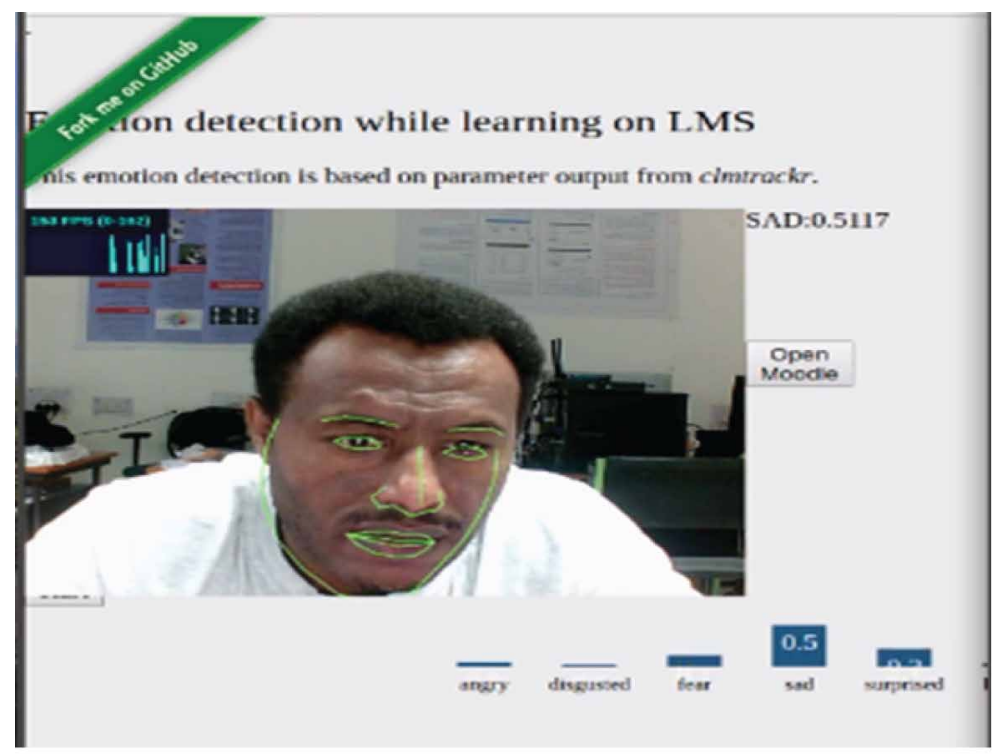

Figure 3. Facial emotion recognition rate downloaded as log file in csv format at the end of 5 minutes

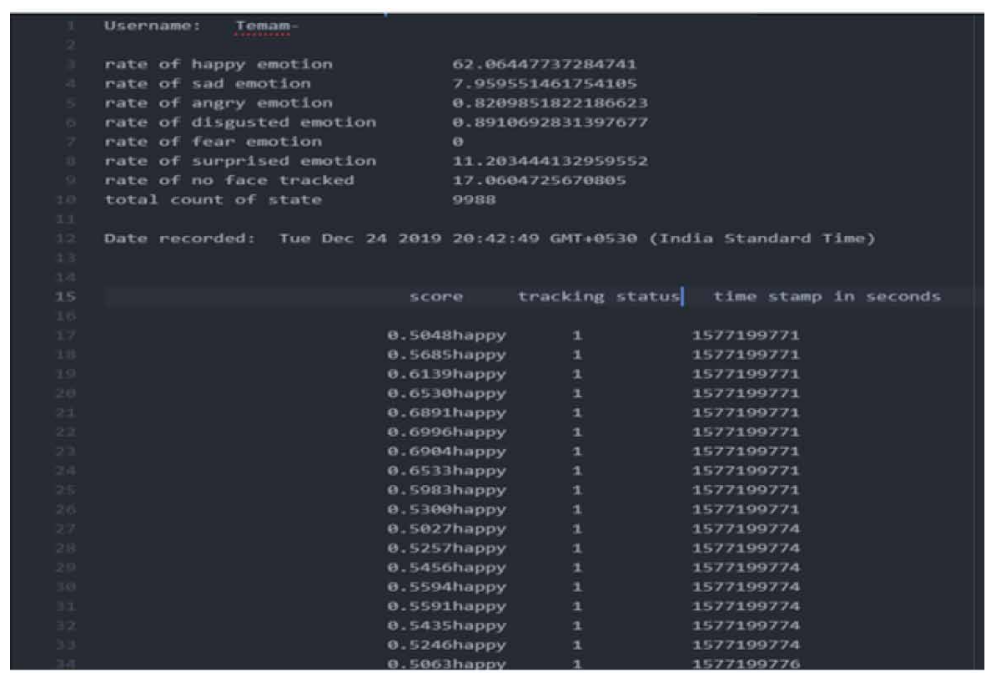

facial expressions were being tracked. For model building experiment, the log file of the interaction with the LMS was later extracted. This log file was categorized in 5 minutes sample. At the same time, the log file of the rate of facial emotion was downloaded every 5 minutes. For the model building experiment, each interaction of the participants in the experiment was recorded with screen recording software. The recorded video interaction was used for labeling the engagement levels of each participant for analysis purpose. The labelling task was performed by viewing 10 -second video clips from the recorded interaction videos and assigning a number (between 1 and 4) to rate each video frame, as explained in Table 5. 
Figure 4. A student was interacting with content while his facial emotion was recognized in real time

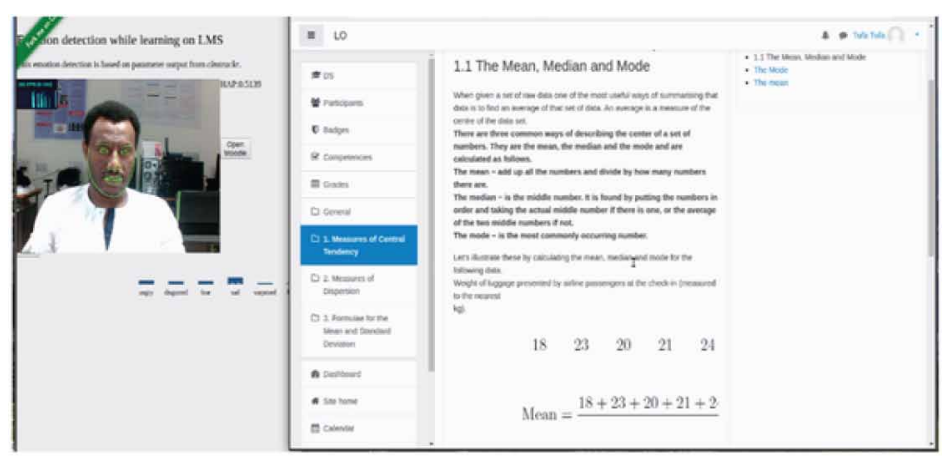

\section{ANALYSIS OF DATA}

After collecting the data, the researchers performed detailed analysis. The researchers correlated the interactions data to four levels of engagement applying Pearson correlation analysis. The researchers determined the significant features that affected a given level of engagement. The significant features were applied in building the student engagement prediction model.

\section{Pre-Processing}

For each participant, the researchers captured the video of the interaction with the LMS for 30 minutes. Table 6 shows points for 4 levels of engagement for a single participant.

For example, 25 in Table 6 (1st row and 4th column) indicate 25 frames where this participant has been found to be at very high levels of engagement (ENG-VH) in that particular time interval.

The researchers calculated the average of the levels of engagement for each participant for the whole 25 minutes as shown in Table 7.

Corresponding to the labelling, categorizing the log file in sample of 5 minutes was done for the three factors consisting of 13 features. For each participant, and for each of the 13 features in the three factors, the researchers would have 5 samples of 5 minutes length in 25 minutes long interaction. Table 8 shows the 5 samples of the three factors for a single participant.

In Table 8, NR=Number of Replies, TPR=Time between Post and Replies, $\mathrm{TF}=$ Time in the Forum, TA=Time of Assignment Submission, NCV=Number of Content View, $\mathrm{SC}=$ Score of quiz, $\mathrm{TRC}=$ Time to Read Content, $\mathrm{ANG}=$ Anger, $\mathrm{DIS}=$ Disgust, FEA=Fear, $\mathrm{SAD}=$ sad, $\mathrm{SUR}=$ Surprise, $\mathrm{HAP}=$ Happy.

Table 3. Summary of tasks performed

\begin{tabular}{|l|l|l|l|}
\hline S/no & $\begin{array}{l}\text { Task or learning activity for capturing data } \\
\text { through feature }\end{array}$ & Type of feature & Specific feature \\
\hline 1 & Lesson, Quiz and Assignment & Behavioral features & $\begin{array}{l}\text { Number of content view (NCV), time } \\
\text { to read content (TRC), score (SC) } \\
\text { and Time to submit assignment (TA) }\end{array}$ \\
\hline 2 & Discussion forum & Collaboration feature & $\begin{array}{l}\text { time between posts and replies } \\
\text { (TPR), time in the forum (TF) and } \\
\text { number of replies (NR) }\end{array}$ \\
\hline 3 & $\begin{array}{l}\text { A student sits in front of a computer with a } \\
\text { webcam and allowing face tracking }\end{array}$ & Emotional feature & $\begin{array}{l}\text { Rates of the basic emotions which } \\
\text { are: disgust (DIS), angry (ANG), fear } \\
\text { (FEA), sad (SAD), surprise (SUR) } \\
\text { and happy (HAP), }\end{array}$ \\
\hline
\end{tabular}


Table 4. Three types of features: Behavioural features, collaboration features, and emotional features

\begin{tabular}{|c|c|c|c|}
\hline Type of feature & Feature name & Feature description & Remark \\
\hline & Engagement levels & $\begin{array}{l}\text { There were four engagement levels that were } \\
\text { annotated by human observer from a screen record of } \\
\text { interaction with the LMS in } 30 \text { minutes which were: } \\
\text { very low (VL) engagement level, low (L) } \\
\text { engagement level, high (H) engagement level and } \\
\text { very high (VH) engagement level following the } \\
\text { works of Whitehill et.al. (2014) and Kaur } \\
\text { et.al.(2018)(explained below). }\end{array}$ & $\begin{array}{l}\text { Dependent } \\
\text { variable }\end{array}$ \\
\hline \multirow[t]{4}{*}{$\begin{array}{l}\text { Behavioural } \\
\text { features }\end{array}$} & $\begin{array}{lll}\begin{array}{l}\text { Number } \\
\text { view(NCV) }\end{array} & \text { of content } \\
\end{array}$ & $\begin{array}{l}\text { The number of content view that is stored in the log } \\
\text { file categorized or sampled in } 5 \text { minutes }\end{array}$ & \multirow[t]{13}{*}{$\begin{array}{l}\text { Independent } \\
\text { variables }\end{array}$} \\
\hline & $\begin{array}{ll}\text { Time of reading } \\
\text { content(TRC) }\end{array}$ & $\begin{array}{l}\text { The time spent measured in minutes while reading } \\
\text { the content }\end{array}$ & \\
\hline & $\begin{array}{l}\text { Time to } \quad \text { submit } \\
\text { assignment(TA) }\end{array}$ & $\begin{array}{l}\text { Total time spent on assignment as calculated by } \\
\text { subtracting the download time from upload time } \\
\text { measured in minutes }\end{array}$ & \\
\hline & Score(SC) & Final mark a student obtained after taking a quiz & \\
\hline \multirow[t]{3}{*}{$\begin{array}{l}\text { Collaborative } \\
\text { feature }\end{array}$} & Number of replies(NR) & $\begin{array}{l}\text { Number of messages sent by any participant to } \\
\text { someone's post as replies (Number of replies one gets } \\
\text { to his/her posts) }\end{array}$ & \\
\hline & $\begin{array}{l}\text { Time between post and } \\
\text { replies(TPR) }\end{array}$ & $\begin{array}{l}\text { Time spent between someone's post and a reply to it } \\
\text { measured in minutes }\end{array}$ & \\
\hline & Time in the forum(TF) & Total time used in the forum measured in minutes & \\
\hline \multirow{6}{*}{$\begin{array}{l}\text { Emotional } \\
\text { feature }\end{array}$} & Disgust(DIS) & \multirow{6}{*}{$\begin{array}{l}\text { Rates of basic emotions as recorded through facial } \\
\text { emotion recognition tool to measure levels of } \\
\text { engagement. The log file of the rate of facial } \\
\text { emotion was downloaded every } 5 \text { minutes } \\
\text { automatically. }\end{array}$} & \\
\hline & Anger(ANG) & & \\
\hline & Fear(FEA) & & \\
\hline & Sad(SAD) & & \\
\hline & Surprise(SUR) & & \\
\hline & Happy(HAP) & & \\
\hline
\end{tabular}

After averaging the samples for each participant, in each factor, the results the researchers obtained were shown in Table $9 \mathrm{a}, \mathrm{b}$ and $\mathrm{c}$.

\section{Correlation Analysis}

The researchers used Pearson correlation coefficient to analyze data. Values between 0.3 and 0.7 $(-0.3$ and -0.7$)$ indicate a moderate positive (negative) linear relationship. Values between 0.7 and $1.0(-0.7$ and -1.0$)$ indicate a strong positive (negative) linear relationship (Bruce Ratner, 2003). The researchers used MS Excel 2010 for the analysis. The correlation was computed between the four engagement levels and the features. Table 10 summarizes the significant features which were identified from the correlation analysis result.

Table 5. Categories of the engagement for labelling the recorded video of interaction based on the works of Whitehill et al. (2014) and Kaur et al. (2018)

\begin{tabular}{|l|l|l|}
\hline Engagement intensity & Meaning & Point given \\
\hline VERY LOW $($ VL) & Not engaged at all & 1 \\
\hline LOW $($ L) & Barely engaged & 2 \\
\hline HIGH $(\mathrm{H})$ & Engaged in the content & 3 \\
\hline VERY HIGH $(\mathrm{VH})$ & Very engaged & 4 \\
\hline
\end{tabular}


Table 6. The four levels of engagement data for a single participant

\begin{tabular}{|l|l|r|r|r|r|}
\hline \multirow{2}{*}{ Participant } & \multirow{2}{*}{ Time Interval } & \multicolumn{2}{|c|}{ Engagement Levels } & & \\
\cline { 2 - 6 } & & ENG -VL & ENG - $\mathbf{~}$ & ENG -H & ENG -VH \\
\hline \multirow{3}{*}{ Participant 1} & $0-5 \mathrm{~min}$ & 0 & 0 & 5 & 25 \\
\cline { 2 - 6 } & $5-10 \mathrm{~min}$ & 0 & 0 & 0 & 30 \\
\cline { 2 - 6 } & $10-15 \mathrm{~min}$ & 0 & 0 & 2 & 28 \\
\hline & $15-20 \mathrm{~min}$ & 0 & 0 & 9 & 21 \\
\cline { 2 - 6 } & $20-25 \mathrm{~min}$ & 0 & 0 & 25 & 5 \\
\hline
\end{tabular}

\section{MODEL BUILDING}

The student engagement prediction model that the researchers built was based on the significant features identified for the four levels of engagement.

\section{Non-Linear Regression Analysis and Result}

After finding the configuration of initial values of parameters for the non-linear regression of the data for the four levels of engagement, the next step was to find the better fit using SOLVER. Table 11 displays the fit as calculated by SOLVER. The table illustrates the best fit and an improvement over the fit provided by the initial parameter values.

Table 7. Average of the four levels of engagement labelled for all participants

\begin{tabular}{|l|l|r|r|r|r|}
\hline Participant & Time Interval & ENG-VL & ENG-L & ENG-H & ENG-VH \\
\hline Participant 1 & $0-25 \mathrm{~min}$ & 0 & 0 & 8.2 & 21.8 \\
\hline Participant 2 & $0-25 \mathrm{~min}$ & 0 & 0 & 0.4 & 29.6 \\
\hline Participant 3 & $0-25 \mathrm{~min}$ & 0.4 & 0 & 6.8 & 22.8 \\
\hline Participant 4 & $0-25 \mathrm{~min}$ & 0 & 0.6 & 1.4 & 28 \\
\hline Participant 5 & $0-25 \mathrm{~min}$ & 0 & 0.4 & 5.6 & 24 \\
\hline Participant 6 & $0-25 \mathrm{~min}$ & 0 & 0.2 & 1.4 & 28.4 \\
\hline Participant 7 & $0-25 \mathrm{~min}$ & 0 & 1.2 & 8.4 & 20.4 \\
\hline Participant 8 & $0-25 \mathrm{~min}$ & 0.4 & 1.2 & 2.8 & 25.6 \\
\hline Participant 9 & $0-25 \mathrm{~min}$ & 0 & 0 & 4.4 & 25.6 \\
\hline Participant 10 & $0-25 \mathrm{~min}$ & 0 & 0 & 0.8 & 29.2 \\
\hline Participant 11 & $0-25 \mathrm{~min}$ & 0.6 & 2.2 & 4 & 23.2 \\
\hline Participant 12 & $0-25 \mathrm{~min}$ & 0 & 0 & 1.6 & 28.4 \\
\hline
\end{tabular}


Table 8.5 samples of 5 minutes length of the collaboration features, behavioural features, and emotional features for one participant

\begin{tabular}{|c|c|c|c|c|c|c|c|c|}
\hline Participant & $\begin{array}{l}\text { Time } \\
\text { Interval }\end{array}$ & Feature & & & & & & \\
\hline \multirow{30}{*}{ Partieipant 1} & $0-5 \min$ & Collaboration & NR & TPR & TF & & & \\
\hline & & & 0 & 0 & 0 & & & \\
\hline & & Behaviounal & TA & $\mathrm{NCV}$ & sc & TRC & & \\
\hline & & & o & 13 & 1.43 & 4 & & \\
\hline & & Emotional & ANG & DIS & FEA & SAD & SUR & HAP \\
\hline & & & 10.3 & 59.67 & 1.16 & 6.15 & 1.16 & 9.88 \\
\hline & $5-10 \mathrm{~min}$ & Collaboration & NR & TPR & TF & & & \\
\hline & & & 0 & 0 & 2 & & & \\
\hline & & Behavioural & TA & $\mathrm{NCV}$ & sc & TRC & & \\
\hline & & & 0 & 7 & 0 & 2 & & \\
\hline & & Emotional & ANG & DIS & FEA & SAD & SUR & HAP \\
\hline & & & 16.36 & 54.17 & 0.35 & 2.26 & 1.14 & 4.44 \\
\hline & $10-15 \mathrm{~min}$ & Collaboration & NR & TPR & TF & & & \\
\hline & & & 0 & 0 & 0 & & & \\
\hline & & Behavioural & TA & NCV & $\mathrm{SC}$ & TRC & & \\
\hline & & & 0 & 4 & 7.14 & 1 & & \\
\hline & & Emotional & ANG & DIS & FEA & SAD & SUR & HAP \\
\hline & & & 5.81 & 18.19 & 0.25 & 10.5 & 16.54 & 36.64 \\
\hline & 15-20min & Collaboration & NR & TPR & TF & & & \\
\hline & & & 0 & 0 & 0 & & & \\
\hline & & Behaviournal & TA & NCV & SC & TRC & & \\
\hline & & & 0 & 4 & 0 & 3 & & \\
\hline & & Emotional & ANG & DIS & FEA & SAD & SUR & HAP \\
\hline & & & 5.5 & 17.28 & 0.24 & 10.12 & 16.94 & 38.49 \\
\hline & $20-25 \min$ & Collaboration & NR & TPR & TF & & & \\
\hline & & & 1 & 8689 & 0 & & & \\
\hline & & Behavioural & TA & $\mathrm{NCV}$ & sc & TRC & & \\
\hline & & & 0 & 4 & 8.57 & 2 & & \\
\hline & & Emotional & ANG & DIS & FEA & SAD & SUR & HAP \\
\hline & & & 4.48 & 14.2 & 0.2 & 9.32 & 17.81 & 38.05 \\
\hline
\end{tabular}

\section{Proposed Model}

The researchers obtained Eq. 1-4 as the final proposed model, where the values of a, b and c were

Table 9a. Average of 5 samples of 5 minutes length of the collaboration features for all participants (TF and TPR were measured in minutes)

\begin{tabular}{|l|r|r|r|}
\hline Participant & NR & TPR & TF \\
\hline Participant 1 & 0.2 & 1737.8 & 0.4 \\
\hline Participant 2 & 0.8 & 5710.8 & 1 \\
\hline Participant 3 & 0.2 & 1730.4 & 1 \\
\hline Participant 4 & 0.6 & 2916.4 & 1 \\
\hline Participant 5 & 0.4 & 2883.4 & 1.6 \\
\hline Participant 6 & 0.2 & 512.6 & 2.4 \\
\hline Participant 7 & 0 & 0 & 0.4 \\
\hline Participant 8 & 0.4 & 1044 & 1.6 \\
\hline Participant 9 & 0.4 & 515.6 & 1.4 \\
\hline Participant 10 & 0.4 & 5774.8 & 0.4 \\
\hline Participant 11 & 0.6 & 824.6 & 1.4 \\
\hline Participant 12 & 0.4 & 1665 & 0.8 \\
\hline
\end{tabular}


Table $9 \mathrm{~b}$. Average of 5 samples of 5 minutes length of the collaboration features for all participants (TA and TRC were measured in minutes)

\begin{tabular}{|l|r|r|r|r|}
\hline Participant & \multicolumn{1}{|l|}{ TA } & NCV & SC & TRC \\
\hline Participant 1 & 0 & 6.4 & 3.428 & 2.4 \\
\hline Participant 2 & 4303.6 & 3.4 & 3.142 & 2 \\
\hline Participant 3 & 926.2 & 9.2 & 3.428 & 2.6 \\
\hline Participant 4 & 1214.2 & 5.8 & 5.428 & 3 \\
\hline Participant 5 & 4343.4 & 4.6 & 3.428 & 2.4 \\
\hline Participant 6 & 2402.2 & 3.8 & 5.428 & 1.8 \\
\hline Participant 7 & 2306.6 & 6.8 & 5.428 & 3.4 \\
\hline Participant 8 & 0 & 3 & 4 & 2 \\
\hline Participant 9 & 4061.8 & 3 & 2.286 & 2 \\
\hline Participant 10 & 2390.4 & 4.8 & 1.142 & 2.8 \\
\hline Participant 11 & 1211 & 4 & 5.142 & 3.4 \\
\hline Participant 12 & 4639 & 3.8 & 3.142 & 2.2 \\
\hline
\end{tabular}

Table 9c. Average of 5 samples of 5 minutes length of emotional features for all participants

\begin{tabular}{|l|r|r|r|r|r|r|}
\hline Participant & \multicolumn{1}{|l|}{ ANG } & \multicolumn{1}{l|}{ DIS } & FEA & \multicolumn{1}{l|}{ SAD } & \multicolumn{1}{l|}{ SUR } & \multicolumn{1}{l|}{ HAP } \\
\hline Participant 1 & 8.49 & 32.702 & 0.44 & 7.67 & 10.718 & 25.5 \\
\hline Participant 2 & 3.692 & 18.62 & 13.976 & 4.842 & 9.198 & 47.602 \\
\hline Participant 3 & 0.47 & 0.448 & 0.03 & 2.914 & 4.954 & 33.124 \\
\hline Participant 4 & 2.536 & 9.286 & 0.02 & 4.642 & 7.978 & 47.7166 \\
\hline Participant 5 & 2.22 & 2.828 & 19.538 & 11.44 & 28.696 & 15.868 \\
\hline Participant 6 & 6.978 & 7.29 & 0.002 & 0.13 & 7.47 & 76.854 \\
\hline Participant 7 & 1.738 & 6.064 & 1.548 & 20.796 & 60.158 & 9.56 \\
\hline Participant 8 & 15.22 & 16.07 & 2.992 & 13.89 & 25.888 & 25.112 \\
\hline Participant 9 & 3.888 & 7.534 & 13.998 & 46.29 & 5.614 & 22.598 \\
\hline Participant 10 & 38.084 & 43.442 & 0.004 & 1.768 & 2.912 & 13.612 \\
\hline Participant 11 & 1.542 & 5.432 & 0.03 & 3.818 & 45.128 & 43.382 \\
\hline Participant 12 & 0.196 & 0.868 & 0 & 1.288 & 4.428 & 93.206 \\
\hline
\end{tabular}

taken from Table 11 for the corresponding features and engagement levels. The equations and the engagement level ranges were presented in Table 12.

\section{VALIDATING THE PROPOSED MODEL}

The researchers aim to validate the student engagement prediction model through experiment. For achieving the objective, the researchers collected empirical data related to interaction with learning activities in LMS. The researchers also applied self-reporting as ground truth data. The prediction of the model was compared with the self-reporting. Each of the 12 participants took 25 minutes for the interaction. At the end of the 25 minutes, the participants filled a questionnaire which is a Likert scale of 5 scales and of 19 items taken from the work of Dixon, (2015) for self-reporting the engagement levels they experienced. The data collected after the interaction with the LMS and averaged for 25 minutes from the log file and face tracking tool during the validation experiment was given in Table 13. The researchers also applied the model built on the collected data to classify each of the participants in to one of the four engagement levels after computation. The classified engagement levels after 
Table 10. Summary of significant features

\begin{tabular}{|c|c|c|c|}
\hline $\begin{array}{l}\text { Engagement } \\
\text { level }\end{array}$ & Type of factor & Significant feature & $\begin{array}{l}\text { Total number of } \\
\text { significant } \\
\text { features }\end{array}$ \\
\hline \multirow[t]{3}{*}{ Very low (VL) } & Collaboration & & \multirow[t]{3}{*}{2} \\
\hline & Behavioural & Time of assignment submission (TA) & \\
\hline & Emotional & Surprise (SUR) & \\
\hline \multirow[t]{3}{*}{ Low (L) } & Collaboration & Time between post and reply(TPR) & \multirow[t]{3}{*}{5} \\
\hline & Behavioural & $\begin{array}{l}\text { Time of assignment submission (TA), Time to read content } \\
\text { (TRC), Score of quiz (SC) }\end{array}$ & \\
\hline & Emotional & Surprise (SUR) & \\
\hline \multirow[t]{3}{*}{ High $(\mathrm{H})$} & Collaboration & $\begin{array}{l}\text { Number of replies(NR), Time between post and reply(TPR) } \\
\text { and Time in the forum (TF) }\end{array}$ & \multirow[t]{3}{*}{10} \\
\hline & Behavioural & $\begin{array}{l}\text { Time of assignment submission (TA), Time to read content } \\
\text { (TRC), Number of content view (NCV) }\end{array}$ & \\
\hline & Emotional & $\begin{array}{l}\text { Anger (ANG), Sad emotion(SAD), Surprise (SUR) and Happy } \\
\text { emotion(HAP) }\end{array}$ & \\
\hline \multirow[t]{3}{*}{ Very high $(\mathrm{VH})$} & Collaboration & Number of replies(NR), Time between post and reply(TPR) & \multirow[t]{3}{*}{9} \\
\hline & Behavioural & $\begin{array}{l}\text { Time of assignment submission (TA), Time to read content } \\
\text { (TRC), Number of content view (NCV) and Score of quiz } \\
\text { (SC) }\end{array}$ & \\
\hline & Emotional & Anger (ANG), Surprise (SUR) and Happy emotion(HAP) & \\
\hline
\end{tabular}

Table 11. The fit as calculated by SOLVER for the four levels of engagement

\begin{tabular}{|c|c|c|c|c|c|c|c|c|c|c|c|c|}
\hline & \multicolumn{12}{|c|}{ Features } \\
\hline & & NR & TPR & TF & NCV & TRC & TA & ANG & SUR & HAP & SAD & SC \\
\hline $\begin{array}{l}\text { Engagemen } \\
\text { t levels }\end{array}$ & $\begin{array}{l}\text { Para } \\
\text { mete } \\
\text { rs }\end{array}$ & & & & & & & & & & & \\
\hline \multirow{4}{*}{$\begin{array}{l}\text { Very high } \\
\text { level(VH) }\end{array}$} & $\mathrm{a}$ & 0 & 0.0000001 & & 0.02 & -0.8 & 0 & 0.002 & -0.001 & -0.001 & & 0.4 \\
\hline & b & 15.28 & $-4.00 \mathrm{E}-04$ & & -2.00 & -0.7 & 0.001 & 0.02 & -0.09 & 0.09 & & -4 \\
\hline & c & 17.89 & 24.00 & & 33.00 & 30 & 20 & 24 & 27 & 23 & & 33 \\
\hline & $\mathrm{R}^{2}$ & 1 & 0.96 & & $\begin{array}{l}0.98 \\
\end{array}$ & 0.97 & 0.95 & 1.0 & 0.93 & 0.99 & & 1.0 \\
\hline \multirow{4}{*}{$\begin{array}{l}\text { High } \\
\text { level }(H)\end{array}$} & $\mathrm{a}$ & 15 & $8 \mathrm{E}-08$ & 2 & -0.02 & -1.28 & 0 & -0.002 & 0.003 & 0 & -1.28 & \\
\hline & b & -15 & -0.0004 & -3 & 2 & 9.5 & -0.001 & $\begin{array}{r}-0.03 \\
\end{array}$ & 0.01 & -0.12 & 9.5 & \\
\hline & $\mathrm{c}$ & 9 & 6 & 5 & -3 & -9.3 & 9.8 & 6 & 3 & 7.5 & -9.3 & \\
\hline & $\mathrm{R}^{2}$ & 0.99 & 1.0 & 0.97 & 0.99 & 0.91 & 0.99 & 0.97 & 0.99 & 1.0 & 0.91 & \\
\hline \multirow[t]{4}{*}{$\begin{array}{l}\text { Low } \\
\text { level(L) }\end{array}$} & a & & $\begin{array}{r}0.0000000 \\
8 \\
\end{array}$ & & & 1.7 & $-6 \mathrm{E}-08$ & & -0.002 & & & 0.06 \\
\hline & b & & -0.0004 & & & -7.5 & 0.0002 & & 0.06 & & & 0.05 \\
\hline & $\mathrm{c}$ & & 0.9 & & & 8.6 & 0.7 & & 0.3 & & & -0.5 \\
\hline & $\mathrm{R}^{2}$ & & 0.98 & & & 0.99 & 0.80 & & 0.91 & & & 0.92 \\
\hline \multirow{5}{*}{$\begin{array}{l}\text { Very low } \\
\text { level(VL) }\end{array}$} & $\mathrm{a}$ & & & & & & $-6 \mathrm{E}-08$ & & -0.0006 & & & \\
\hline & b & & & & & & 0.0002 & & 0.02 & & & \\
\hline & c & & & & & & 0.3 & & -0.07 & & & \\
\hline & $\mathrm{R}^{2}$ & & & & & & & & & & & \\
\hline & & & & & & & 0.90 & & 0.99 & & & \\
\hline
\end{tabular}

computed by the model were given in Table 14. The researchers then matched the engagement levels classified by the model and the self-report. Inspired by the work of Samara et al., (2019), scale 1 or 2 were mapped to very low (VL) engagement levels, and scale 3 was mapped to low (L) engagement level, scale 4 was mapped to high $(\mathrm{H})$ engagement level, and scale 5 was mapped to very high $(\mathrm{VH})$ engagement level. The maximum value of the response was also used to classify the participant in to one of the four engagement levels based on the work of Bosse et al., (2013). The responses given through the self-report and the classified engagement levels based on the works of Bosse et al., (2013) and Samara et al., (2019) is given in Table 15.

The researchers determined the engagement levels using the proposed model according to the following algorithm listed in Figure 5. 
Table 12. The equations and the engagement level ranges

\begin{tabular}{|c|c|c|c|}
\hline \multirow[t]{2}{*}{ Eq.\# } & \multirow[t]{2}{*}{ Equation } & \multicolumn{2}{|c|}{ Range } \\
\hline & & Min. & Max. \\
\hline 1 & $\begin{array}{l}V L=0.02 \times S U R+0.23 \\
\text { Where } 2.9 \leq \text { SUR } \leq 11\end{array}$ & $=0$ & $=2$ \\
\hline 2 & $\begin{array}{c}\mathrm{L}=0.06 \times \mathrm{SC}^{2}+0.05 \times \mathrm{SC}+1.7 \times \mathrm{TRC}^{2}-7.5 \times \mathrm{TRC}+0.06 \times \mathrm{SUR}+10, \\
\text { Where, } \quad \mathrm{TRC} \geq 2.4 \text { and } 2.9 \leq \mathrm{SUR} \leq 11\end{array}$ & $>2$ & $=7$ \\
\hline 3 & $\begin{array}{l}\mathrm{H}=15 \times \mathrm{NR}^{2}-15 \times \mathrm{NR}+2 \times \mathrm{TF}^{2}-3 \times \mathrm{TF}-0.02 \times \mathrm{NCV}^{2}+2 \times \mathrm{NCV}-1.28 \times \mathrm{TRC}^{2}+ \\
\quad 9.5 \times \mathrm{TRC}-0.03 \times \mathrm{ANG}+0.01 \times \mathrm{SUR}-0.123 \times \mathrm{HAP}+0.43 \times \mathrm{SAD}+35.5\end{array}$ & $>7$ & $=62$ \\
\hline 4 & $\begin{array}{l}\mathrm{VH}=15.3 \times \mathrm{NR}+0.4 \times \mathrm{SC}^{2}-4 \times \mathrm{SC}+0.02 \times \mathrm{NCV}^{2}-2 \times \mathrm{NCV}-0.8 \times \mathrm{TRC}^{2}-0.7 \times \mathrm{TRC}+ \\
\quad 0.02 \times \mathrm{ANG}-0.09 \times \mathrm{SUR}+0.09 \times \mathrm{HAP}+232, \\
\text { Where, } 3 \leq \mathrm{NCV} \leq 9.2,1.8<\mathrm{TRC} \leq 3.4 \text {, and } 0 \leq \mathrm{HAP} \leq 43\end{array}$ & $>62$ & $=254$ \\
\hline
\end{tabular}

Table 13. The data collected after the interaction with the LMS, sampled in 5 minutes and averaged for 25 minutes from the log file and face tracking tool during the validation experiment

\begin{tabular}{|r|l|r|r|r|r|r|r|r|r|r|r|r|}
\hline S/no & Participant & TRC & NCV & TA & TF & SC & NR & \multicolumn{1}{l|}{ TPR } & ANG & SAD & HAP & SUR \\
\hline 1 & Participant 1 & 1.4 & 2.4 & 1.8 & 1.4 & 2 & 0 & 0 & 4.82 & 37.38 & 38.01978 & 6.92 \\
\hline 2 & Participant 2 & 1 & 2.4 & 1.4 & 1 & 2 & 0 & 0 & 36.62 & 5.12 & 24.16027 & 10.34 \\
\hline 3 & Participant 3 & 1.2 & 2.4 & 2.4 & 2 & 1.2 & 0 & 0 & 30.42 & 0.48 & 32.96322 & 1.48 \\
\hline 4 & Participant 4 & 1.6 & 2.4 & 1.8 & 1.4 & 1.6 & 0.8 & 576 & 35.16 & 1.06 & 13.67896 & 0.68 \\
\hline 5 & Participant 5 & 1.6 & 2.4 & 1.2 & 0.8 & 2 & 0 & 0 & 0.26 & 16.68 & 79.19 & 3.42 \\
\hline 6 & Participant 6 & 1 & 2.4 & 1.4 & 1.8 & 2 & 0.2 & 288 & 3.04 & 10.36 & 57.76176 & 24.24 \\
\hline 7 & Participant 7 & 1.8 & 2.8 & 1.4 & 1 & 2 & 0.2 & 48 & 10.06 & 2.12 & 41.79586 & 23.98 \\
\hline 8 & Participant 8 & 1.6 & 1.6 & 2 & 1.6 & 2 & 0.4 & 576 & 20.38 & 2.2 & 47.06668 & 9.64 \\
\hline 9 & Participant 9 & 2.6 & 4.6 & 1.8 & 2.2 & 1.6 & 0.8 & 864 & 24.1 & 2.96 & 28.2219 & 16.2 \\
\hline 10 & Participant 10 & 3.4 & 4.4 & 1.6 & 1.2 & 2 & 0.8 & 864 & 3.72 & 0.06 & 60.21171 & 1.74 \\
\hline 11 & Participant 11 & 0.8 & 2.4 & 1.4 & 1.6 & 2 & 0.8 & 864 & 16.6 & 0.94 & 28.09114 & 23.06 \\
\hline 12 & Participant 12 & 1.4 & 2.8 & 3.2 & 3.2 & 2 & 0.4 & 1440 & 9.48 & 17.82 & 48.35905 & 7.6 \\
\hline
\end{tabular}

Thus from the analysis, the proposed model was able to correctly predict the engagement levels of 10 participants out of 12 . The accuracy of the model was found to be $83.3 \%$.

\section{DISCUSSION}

The researchers proposed a student engagement prediction models using 9 features out of 13 that were significant to affect the levels of student engagement and emerged in the final models. The researchers built a student engagement prediction model that predicts an engagement level using these features through non-linear regression techniques. The features were of three categories namely: behavioural, collaboration and emotional features. The features were from interaction with an LMS and facial emotion recognition tool. A technique that fit a non-linear function to the data was implemented. 
Table 14. The classified engagement levels after computed by the model based on the given algorithm

\begin{tabular}{|c|c|c|c|c|c|c|}
\hline S/no & Participant & $\mathbf{Y}_{\mathbf{V L}}$ & $\mathbf{Y}_{\mathbf{L}}$ & $\mathbf{Y}_{\mathrm{H}}$ & $\mathbf{Y}_{\mathrm{VI}}$ & $\begin{array}{l}\text { Decision after model } \\
\text { computation }\end{array}$ \\
\hline 1 & Participant 1 & 0.3684 & 10.7552 & 46.22417 & 228.4954 & VH \\
\hline 2 & Participant 2 & 0.4368 & 10.9604 & 46.63949 & 227.5762 & VH \\
\hline 3 & Participant 3 & 0.23 & 10.1464 & 44.99572 & 231.2179 & VH \\
\hline 4 & Participant 4 & 0.23 & 10.2336 & 49.83329 & 240.7371 & VH \\
\hline 5 & Participant 5 & 0.2984 & 10.5452 & 48.44643 & 225.2974 & VH \\
\hline 6 & Participant 6 & 0.23 & 10.34 & 43.5061 & 226.5392 & VH \\
\hline 7 & Participant 7 & 0.23 & 10.34 & 47.20471 & 226.6126 & VH \\
\hline 8 & Participant 8 & 0.4228 & 10.9184 & 41.6138 & 231.26 & VH \\
\hline 9 & Participant 9 & 0.23 & 2.2256 & 57.56451 & 224.4232 & VH \\
\hline 10 & Participant 10 & 0.2648 & 4.5964 & 53.94156 & 217.717 & VH \\
\hline 11 & Participant 11 & 0.23 & 10.34 & 43.64719 & 238.6248 & VH \\
\hline 12 & Participant 12 & 0.382 & 10.796 & 49.64044 & 231.2256 & VH \\
\hline
\end{tabular}

Table 15. The responses given through the self-report and the classified engagement levels

\begin{tabular}{|r|l|r|r|r|r|r|l|}
\hline S/no & & & & & & & \\
Participant & Scale 1 & Scale 2 & Scale 3 & Scale 4 & Scale 5 & $\begin{array}{l}\text { Decision based on Bosse } \\
\text { et al.,(2019) }\end{array}$ \\
\hline 1 & Participant 1 & 0 & 1 & 6 & 4 & 8 & VH \\
\hline 2 & Participant 2 & 2 & 3 & 8 & 5 & 1 & L \\
\hline 3 & Participant 3 & 0 & 0 & 1 & 4 & 14 & VH \\
\hline 4 & Participant 4 & 3 & 0 & 0 & 3 & 13 & VH \\
\hline 5 & Participant 5 & 2 & 1 & 3 & 4 & 9 & VH \\
\hline 6 & Participant 6 & 0 & 3 & 3 & 3 & 10 & VH \\
\hline 7 & Participant 7 & 2 & 3 & 2 & 5 & 7 & VH \\
\hline 8 & Participant 8 & 1 & 1 & 3 & 4 & 10 & VH \\
\hline 9 & Participant 9 & 0 & 0 & 5 & 5 & 9 & VH \\
\hline 10 & Participant 10 & 0 & 0 & 4 & 7 & 8 & VH \\
\hline 11 & Participant 11 & 2 & 5 & 7 & 5 & 0 & L \\
\hline 12 & Participant 12 & 0 & 0 & 0 & 3 & 16 & VH \\
\hline
\end{tabular}

A polynomial (quadratic) regression was used to capture the data in non-linear relationship (Bruce and Bruce, 2017). 


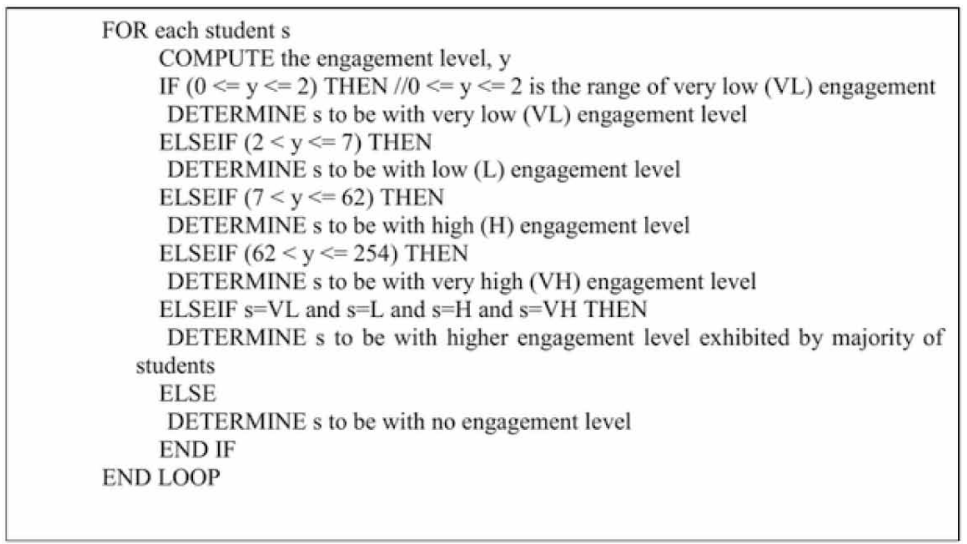

The researchers performed validation of the results of the study. The proposed model was able to correctly predict the engagement levels of 10 students out of 12 . The accuracy of the model was found to be $83.3 \%$. However, the accuracy was not greater than $83.3 \%$, because of the fact that the students were unable to accurately distinguish and report their actual level of engagement through the selfreport questionnaire (Samara et al. 2019). Moreover, D'Mello et al., (2017) explained that agreement between external observers used for annotation while building the model and self-reporting used for annotation while validation purpose is very low. The students may consciously or unconsciously conceal his or her real emotions as shown by observable cues like facial, however will still reveal their internal feelings by invisible cues like bio signals (Gunes and Pantic, 2010).

One of the contributions of this study is that the researchers built a student engagement prediction model from three factors namely behavioural, collaboration and emotional factors as engagement is a multifaceted construct. Moreover, the student engagement prediction model predicted student engagement levels in smaller time scale that is 5 minutes with more than $83 \%$ accuracy. One implication of this contribution is the fact that providing students with support and guidance as soon as possible to lessen the danger of disengagement is critical (Falkner and Falkner, 2012).

The other contribution of this study was the finding that two collaborative features which are Time in the forum (TF) was significant in predicting high and Number of replies (NR) was significant in predicting both high and very high levels of engagement. This finding has implication that these two collaborative features should be supported to lead students to high and very high levels of student engagement in asynchronous online learning. Moreover, this has implication that it confirms that individual interaction of learners with each other has been main influencer of engagement (Redmond et al., 2018). Furthermore, the previously unknown relationships between the features such as number of replies to someone's post and the time between someone's post and replies he/she got and engagement levels as reported by Sadeque et al., (2015) are now known. Time between post and reply played little part in predicting student engagement.

The final contribution was that surprise was an emotional feature that affected very low and low engagement levels. As surprise emotion increases, student disengagement increases very highly. In the attention level, positive affect seems to reduce resources available for effortful processing (Jeon, 2017). Time to read content (TRC) is a behavioural feature that affected low level of engagement. As Time to read content (TRC) increases, student disengagement increases highly. Similar result was also reported by Cocea and Weibelzehl, (2009) that long time spent on the same page was associated with disengagement. Another behavioural feature affecting low engagement was score of quiz. As score increases, student disengagement increases highly. This was unexpected result, but Woolf et 
al., (2009) reported that when problems are easy, a student gets bored. This study implies that these features should be monitored to allow intervention at appropriate times. Two emotional features, disgust and fear did not correlate with any of the engagement levels.

Moreover, the model presented in this paper can help evaluate and improve understanding of asynchronous online student engagement (Hamish Coates, 2007). If a teacher keeps track of the engagement level of students, the learning process will be more effective (Thomas and Jayagopi, 2017).

This research was limited since the study was conducted with few participants. Results would be more generalizable if more participants were considered. Another limitation of the current study was that labelling the recorded interaction into levels of student engagement was done by the researcher. The results may have been affected by the interpretations of the researcher. The model is based on 9 significant features, but not the most important features. The relative importance of the features was not determined. Further study can be done to determine which ones are the most important features. Moreover, further study can be performed to determine if same prediction results can be obtained with the most important features. Implementing brain signal reader to validate the model can be done in future work to get better accuracy of the model. Future research could consider other technologies such as mobile devices. Future research might also analyse other factors of engagement such as cognitive and social engagement factors.

\section{CONCLUSION}

This paper presents a student engagement prediction model using 9 features that were significant out of 13 to affect the levels of student engagement and emerged in the final models. The researchers built the student engagement prediction model using the features through non-linear regression technique. The three factors were behavioral, collaboration and emotional, and measured from interaction with an LMS and facial emotion recognition tool.

Moreover, the researchers built a student engagement prediction model from three factors namely behavioural, collaboration and emotional factors as engagement is a multifaceted construct. Moreover, the student engagement prediction model predicted student engagement levels in smaller time scale that is 5 minutes with more than $83 \%$ accuracy. One implication of this contribution is the fact that providing students with support and guidance as soon as possible to lessen the danger of disengagement is critical.

One emotional feature that is surprise (SUR) and two behavioural features which are Time to read content (TRC) and score of quiz (SC) were found to be indicators of lack of engagement as these were emerged in the final model. This finding has implication that these features should be monitored to allow intervention at appropriate times.

The other finding of this study was that two collaborative features which are Time in the forum (TF) was significant in predicting high and Number of replies (NR) was significant in predicting both high and very high levels of engagement. This study implies that these two collaborative features should be supported to lead students to high and very high levels of student engagement in asynchronous online learning. Moreover, this confirms that individual interaction of learners with each other has been main influencer of engagement (Redmond et al., 2018). Furthermore, the previously unknown relationships between the features such as number of replies to someone's post and the time between someone's post and replies he/she got and engagement levels as reported by Sadeque et al., (2015) are now known. Time between post and reply played little part in predicting student engagement.

The researchers performed validation of the results of the study. The accuracy of identifying students with discrete levels of engagement was determined. The proposed model was able to correctly predict the engagement levels of 10 students out of 12 . The accuracy of the model was found to be 83.3\%. However, the accuracy was not greater than $83.3 \%$, because of the fact that the students were unable to accurately distinguish and report their actual level of engagement through the self-report questionnaire. 
The model was based on 9 significant features, but not the most important features. The relative importance of the features was not determined. Future research might also analyse other factors of engagement such as cognitive and social engagement factors.

\section{ACKNOWLEDGMENT}

We are thankful to all the students who participated in the controlled experiment and in the survey for the data collection. 


\section{REFERENCES}

Al-Alwani. (2016). A Combined Approach to Improve Supervised E-Learning using Multi-Sensor Student Engagement Analysis. American Journal of Applied Sciences.

Altuwairqi, K., Jarraya, S.K., Allinjawi, A., \& Hammami, M. (2018). A new emotion-based affective model to detect student's engagement. Journal of King Saud University-Computer and Information Sciences.

Alyuz, N., Okur, E., Genc, U., Aslan, S., Tanriover, C., \& Esme, A. A. (2017, November). An unobtrusive and multimodal approach for behavioral engagement detection of students. In Proceedings of the 1st ACM SIGCHI International Workshop on Multimodal Interaction for Education (pp. 26-32). doi:10.1145/3139513.3139521

Aslan, S., Alyuz, N., Tanriover, C., Mete, S. E., Okur, E., D’Mello, S. K., \& Arslan Esme, A. 2019, May. Investigating the impact of a real-time, multimodal student engagement analytics technology in authentic classrooms. In Proceedings of the 2019 CHI Conference on Human Factors in Computing Systems (pp. 1-12). doi:10.1145/3290605.3300534

Azcarraga, J., \& Suarez, M. T. (2013). Recognizing student emotions using brainwaves and mouse behavior data. International Journal of Distance Education Technologies, 11(2), 1-15. doi:10.4018/jdet.2013040101

Baker, R.S., \& Rossi, L.M. (2013). Assessing the disengaged behaviors of learners. Design Recommendations for Intelligent Tutoring Systems, 1, 153.

Bosse, T., Gerritsen, C., de Man, J., \& Treur, J. (2013, November). Learning emotion regulation strategies: A cognitive agent model. In 2013 IEEE/WIC/ACM International Joint Conferences on Web Intelligence (WI) and Intelligent Agent Technologies (IAT) (Vol. 2, pp. 245-252). IEEE. doi:10.1109/WI-IAT.2013.116

Brown, A. M. (2001). A step-by-step guide to non-linear regression analysis of experimental data using a Microsoft Excel spreadsheet. Computer Methods and Programs in Biomedicine, 65(3), 191-200. doi:10.1016/ S0169-2607(00)00124-3 PMID:11339981

Bruce \& Bruce. (2017). Practical statistics for data scientists: 50 essential concepts. O’Reilly.

Calvo, R. A., \& D'Mello, S. (2010). Affect detection: An interdisciplinary review of models, methods, and their applications. IEEE Transactions on Affective Computing, 1(1), 18-37. doi:10.1109/T-AFFC.2010.1

Coates, H. (2007). A model of online and general campus-based student engagement. Assessment \& Evaluation in Higher Education, 32(2), 121-141. doi:10.1080/02602930600801878

Cocea, M., \& Weibelzahl, S. (2009). Log file analysis for disengagement detection in e-Learning environments. User Modeling and User-Adapted Interaction, 19(4), 341-385. doi:10.1007/s11257-009-9065-5

Cocea, M., \& Weibelzahl, S. (2011). Disengagement detection in online learning: Validation studies and perspectives. IEEE Transactions on Learning Technologies, 4(2), 114-124. doi:10.1109/TLT.2010.14

D'Mello, S., Dieterle, E., \& Duckworth, A. (2017). Advanced, analytic, automated (AAA) measurement of engagement during learning. Educational Psychologist, 52(2), 104-123. doi:10.1080/00461520.2017.128174 7 PMID:29038607

Dixson, M. D. (2015). Measuring student engagement in the online course: The Online Student Engagement scale (OSE). Online Learning, 19(4), n4. doi:10.24059/olj.v19i4.561

Falkner, N. J., \& Falkner, K. E. (2012, September). A fast measure for identifying at-risk students in computer science. In Proceedings of the ninth annual international conference on International computing education research (pp. 55-62). doi:10.1145/2361276.2361288

Gunes, H., \& Pantic, M. (2010). Automatic, dimensional and continuous emotion recognition. International Journal of Synthetic Emotions, 1(1), 68-99. doi:10.4018/jse.2010101605

Hancock, K. J., \& Zubrick, S. (2015). Children and young people at risk of disengagement from school. Commissioner for Children and Young People.

Henrie, C. R., Halverson, L. R., \& Graham, C. R. (2015). Measuring student engagement in technology-mediated learning: A review. Computers \& Education, 90, 36-53. doi:10.1016/j.compedu.2015.09.005 
Hussain, M., Zhu, W., Zhang, W., \& Abidi, S. M. R. (2018). Student Engagement Predictions in an e-Learning System and Their Impact on Student Course Assessment Scores. Computational Intelligence and Neuroscience, 2018, 2018. doi:10.1155/2018/6347186 PMID:30369946

Jeon, M. (2017). Emotions and affect in human factors and human-computer interaction: Taxonomy, theories, approaches, and methods. In Emotions and affect in human factors and human-computer interaction (pp. 3-26). Academic Press. doi:10.1016/B978-0-12-801851-4.00001-X

Kaur, A., Mustafa, A., Mehta, L., \& Dhall, A. (2018, December). Prediction and localization of student engagement in the wild. In 2018 Digital Image Computing: Techniques and Applications (DICTA) (pp. 1-8). IEEE.

Khazan, O. (2014). This App Reads Your Emotions on Your Face. The Atlantic. https://www.theatlantic.com/ technology/archive/2014/01/this-app-reads-your-emotions-on-your-face/282993/

Kizilcec, R. F., Piech, C., \& Schneider, E. (2013, April). Deconstructing disengagement: analyzing learner subpopulations in massive open online courses. In Proceedings of the third international conference on learning analytics and knowledge (pp. 170-179). doi:10.1145/2460296.2460330

Manwaring, K. C., Larsen, R., Graham, C. R., Henrie, C. R., \& Halverson, L. R. (2017). Investigating student engagement in blended learning settings using experience sampling and structural equation modeling. The Internet and Higher Education, 35, 21-33. doi:10.1016/j.iheduc.2017.06.002

Motz, B., Quick, J., Schroeder, N., Zook, J., \& Gunkel, M. (2019). The validity and utility of activity logs as a measure of student engagement. In The 9th International Learning Analytics \& Knowledge Conference (LAK19), Tempe, AZ. doi:10.1145/3303772.3303789

Rabbany, R., Elatia, S., Takaffoli, M., \& Zaïane, O. R. (2014). Collaborative learning of students in online discussion forums: A social network analysis perspective. In Educational data mining (pp. 441-466). Springer. doi:10.1007/978-3-319-02738-8_16

Ratner. (2003). Statistical Modeling and Analysis for Database Marketing: Effective Techniques for Mining Big Data. Chapman and Hall.

Redmond. (2018). An Online Engagement Framework for Higher Education. Online Learning Journal, 22(1).

Reeve, J., Jang, H., Carrell, D., Jeon, S., \& Barch, J. (2004). Enhancing students' engagement by increasing teachers' autonomy support. Motivation and Emotion, 28(2), 147-169. doi:10.1023/B:MOEM.0000032312.95499.6f

Robal, T., Zhao, Y., Lofi, C., \& Hauff, C. (2018). Towards Real-time Webcam-based Attention Tracking in Online Learning. ACM Annual Meeting of Interactive User Interfaces (IUI).

Sadeque, F., Solorio, T., Pedersen, T., Shrestha, P., \& Bethard, S. (2015, September). Predicting continued participation in online health forums. In Proceedings of the Sixth International Workshop on Health Text Mining and Information Analysis (pp. 12-20). doi:10.18653/v1/W15-2602

Salazar, J. (2010). Staying connected: Online education engagement and retention using educational technology tools. American Society for Clinical Laboratory Science, 23(3), 53-58. doi:10.29074/ascls.23.3_Supplement.53 PMID:20803836

Samara, A., Galway, L., Bond, R., \& Wang, H. (2019). Affective state detection via facial expression analysis within a human-computer interaction context. Journal of Ambient Intelligence and Humanized Computing, 10(6), 2175-2184. doi:10.1007/s12652-017-0636-8

Sharma, P., Joshi, S., Gautam, S., Filipe, V., \& Reis, M. J. (2019). Student Engagement Detection Using Emotion Analysis, Eye Tracking and Head Movement with Machine Learning. arXiv preprint arXiv:1909.12913.

Thomas, C., \& Jayagopi, D. B. (2017, November). Predicting student engagement in classrooms using facial behavioral cues. In Proceedings of the 1st ACM SIGCHI international workshop on multimodal interaction for education (pp. 33-40). doi:10.1145/3139513.3139514

U.S. Department of Education, Office of Educational Technology. (2017). Reimagining the Role of Technology in Education: 2017 National Education Technology Plan Update. Author.

Wang, M. T., \& Degol, J. (2014). Staying engaged: Knowledge and research needs in student engagement. Child Development Perspectives, 8(3), 137-143. doi:10.1111/cdep.12073 PMID:27087833 
Whitehill, J., Serpell, Z., Lin, Y. C., Foster, A., \& Movellan, J. R. (2014). The faces of engagement: Automatic recognition of student engagementfrom facial expressions. IEEE Transactions on Affective Computing, 5(1), 86-98. doi:10.1109/TAFFC.2014.2316163

Woolf, B., Burleson, W., Arroyo, I., Dragon, T., Cooper, D., \& Picard, R. (2009). Affect-aware tutors: Recognising and responding to student affect. International Journal of Learning Technology, 4(3-4), 129-164. doi:10.1504/ IJLT.2009.028804

Zhang, Z., Li, Z., Liu, H., Cao, T., \& Liu, S. (2019). Data-drived Online Learning Engagement Detection via Facial Expression and Mouse Behavior Recognition Technology. Journal of Educational Computing Research.

Abdalganiy Wakjira is a research scholar in the Department of Computer Science and Engineering, IIT Guwahati, India. He holds a Master of Science degree in Information Technology from Sikkim Manipal University, India. He received his Bachelor of Science degree in Computer Science and Information Technology from Haramaya University, Ethiopia.

Samit Bhattacharya is an associate professor in the Department of Computer Science and Engineering, IIT Guwahati, India. He did his MS (by research) and PhD, both in the area of Computer Science and Engineering, from IIT Kharagpur, India. Bhattacharya has more than 10 years of teaching experience at both the undergraduate and postgraduate levels. He is an active researcher in the field of Human-Computer Interaction (HCl) with a focus on user-centric computing. He has more than 50 research publications in reputed international journals, book volumes and conferences under his credit. He has peer-reviewed international journals and attended national and international conferences. He has also received several awards and honours from both the government and the industry for his research and teaching and jointly holds an Indian patent right for Sanyog-an AAC system for Indians afflicted with neuro-motor impairments. More about him and his research interests can be found at his

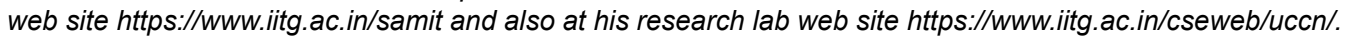

